\title{
Determinants of overdose incidents among illicit opioid users in 5 Canadian cities
}

\author{
Benedikt Fischer, Suzanne Brissette, Serge Brochu, Julie Bruneau, Nady el-Guebaly, Lina Noël, \\ Jürgen Rehm, Mark Tyndall, Cameron Wild, Phil Mun, Emma Haydon, Dolly Baliunas
}

Abstract

Background: Drug overdose is a major cause of death and illness among illicit drug users. Previous research has indicated that most illicit drug users experience nonfatal overdoses and has suggested a variety of factors that are associated with risk of overdose. In this study, we examined the occurrence of and the factors associated with nonfatal overdoses within a Canadian sample of illicit opioid users not enrolled in treatment at the time of study recruitment.

Methods: Interviewers used a standard questionnaire to collect data on sociodemographic characteristics, drug use, health and health care, experience in the criminal justice system and treatment for drug problems; they also performed standard assessments for mental health and infectious disease. The association between overdose and sociodemographic and drug-use factors was examined with $\chi^{2}$ and $t$ test analyses; marginally significant variables were examined with logistic regression to determine independent effects.

Results: A total of 679 subjects were interviewed; 651 provided answers sufficient for this analysis. One hundred and twelve $(17.2 \%)$ of the 651 respondents reported an overdose episode in the previous 6 months. In the logistic regression analysis (after adjustment for sociodemographic factors), homelessness, noninjection use of hydromorphone in the past 30 days and involvement in drug treatment in the past 12 months were predictors of overdose $(p<0.05)$.

Interpretation: Overdose poses a considerable health risk for illicit opioid users. We found that a diverse set of factors was associated with overdose episodes. Prevention efforts will likely be more effective if they can be directed to specific causal factors.

CMAJ 2004;171(3):235-9

$\mathrm{P}$ opulations of illicit drug users are characterized by high rates of illness and death, ${ }^{1,2}$ and drug overdose is a major cause of death. Studies from Australia, Europe and the United States indicate that, overall, annual rates of death due to overdose among illicit drug users are relatively stable, at about $1 \%$ to $2 \% .^{2-5}$ In addition, nonfatal overdose incidents are common and represent an important cause of morbidity among illicit drug users. ${ }^{6}$ For example, among 581 people addicted to narcotics who were admitted to the California Civil Addict Program between 1962 and 1964, there were 284 deaths by the time of the third follow-up, 33 years later; of these, $61(21.5 \%)$ were directly due to drug overdose or poisoning. ${ }^{2}$ Other studies have provided further evidence of high rates of nonfatal overdose among illicit drug users; for example, up to two-thirds of heroin users have reportedly experienced a nonfatal overdose. ${ }^{6-8}$ In yet other studies, up to $89 \%$ of injection drug users surveyed reported having witnessed an overdose..$^{9-11}$

Epidemiologic estimates suggest that there may be as many as 100000 injection drug users in Canada, most of whom use of illicit opioids in some form..$^{12,13}$ Recent estimates have suggested 500 to 1000 overdose deaths per year in Canada during the past decade..$^{14}$ During the 1990s, an overdose crisis developed in British Columbia, fuelled mostly by Vancouver incidents; annual overdose deaths increased substantially, from 67 in 1989 to 361 in 1993 and then to 416 in 1998, peaking at an average of more than 1 overdose death per day. ${ }^{14,15}$ Other data on Canadian drug user populations suggest substantial rates of overdose. Of the 1400 subjects recruited between 1996 and 2000 into the Vancouver Injection Drug User Study, 124 participants died, $41(33.1 \%)$ because of an overdose. ${ }^{16}$ Of 776 actively injecting injection drug users in the same study, 75 (9.7\%) had experienced at least 1 nonfatal overdose in the previous 6-month period. ${ }^{16}$ In a study of illicit opioid users in Toronto from 1996 to 1998 (the Smack Study), 50\% of participants reported at least 1 nonfatal overdose in their lifetime, and 4\% had experienced an overdose in the month before assessment. ${ }^{17}$

Research has identified a variety of risk factors for overdose. The mean age of people who experience a fatal overdose is about 30 years, ${ }^{18-20}$ and such incidents tend to occur after several years of drug use; ;1,21 this pattern runs contrary to the popular misconception that younger, less experienced users are at greatest risk of overdose. ${ }^{5}$ Differences between the sexes appear nonexistent. ${ }^{22-24}$ There is evidence of a relation between poverty and overdose,,$^{19,25,26}$ and injection in public places (which is indicative of poor housing) is a risk factor for overdose. ${ }^{27}$

Drug-use variables associated with overdose include frequency of use, and people who have overdosed on heroin report daily or almost daily use of the drug. ${ }^{7,28}$ Use of alcohol and benzodiazepines in conjunction with opioids is a 
common characteristic of overdose incidents and is associated with greater risk. ${ }^{21,22,29,30}$ Administration of drugs by injection, as opposed to other routes of administration, carries the highest risk of overdose. ${ }^{5,28}$

A complex risk factor for overdose is recent exposure to treatment. ${ }^{31}$ Drug treatment (i.e., detoxification) can lower a user's drug tolerance and increase his or her susceptibility to overdose if nonmedical drug use is continued or reinitiated. One recent study demonstrated, paradoxically, that a group of illicit opioid users who had "successfully" completed detoxification treatment were significantly more likely to die of drug overdose than those who had not completed the treatment. ${ }^{32}$ Other research has shown that unpredictable interactions between prescription and nonprescription drugs during treatment can lead to overdose risk. Such dynamics are particularly pertinent for the initiation phases of methadone treatment, during which disproportionately high rates of overdose have been reported because of opioid dosing dynamics and other (prescription or illicit) substance use. ${ }^{33-35}$ The rate of death due to overdose is greater during initial periods after release from prison, ${ }^{26,36}$ presumably because of an abrupt increase in drug consumption in conjunction with lowered tolerance. High depressive symptom scores have also been associated with overdose incidents. ${ }^{37}$ Finally, a person who has experienced one overdose is at greater risk of another such incident. ${ }^{11}$

Only in a minority of overdose incidents do drug users seek emergency assistance, ${ }^{6,9,11,38}$ largely because of fear of the consequences of revealing their illicit drug use or lack of confidence in the health care system..$^{10,21}$ Increasing support is now being given to the concepts of providing training (e.g., in cardiopulmonary resuscitation) and resources (e.g., naloxone) to drug users as harm reduction strategies. ${ }^{9,39}$

We undertook this study to examine the occurrence of and the factors associated with nonfatal overdose incidents in a cohort of illicit opioid users in 5 Canadian cities.

\section{Methods}

OPICAN is a project of the Interdisciplinary Health Research Team on Illicit Opiate Addiction Research, Treatment and Policy. This project is following a cohort of 679 regular illicit opioid users (i.e., people who use illicit opioids on most days each week for the past year) who were not enrolled in treatment at the time of recruitment. Subjects were recruited by a variety of methods, including dissemination of flyers at user contact points such as needle exchanges, advertisements in community papers and snowball sampling, between March and December 2002 in Vancouver, Edmonton, Toronto, Montréal and Québec. It is not possible to determine statistically defined representativeness in these samples because of the illegal nature of the participants' activities and the impossibility of probabilistic procedures for sampling from a known population (i.e., lack of a sampling frame listing all members of the target population) ${ }^{40}$ However, care was taken to spread information about the study to a large variety of drug user groups, peers and support contacts as suggested by a diverse pool of community liaisons in the local "drug scene" in each city. We are therefore confident that the sample obtained was as typical as possible.

The OPICAN study used a uniform screening and study protocol, and it received approval from a university or hospital ethics research board in each of the 5 cities. Subjects confirmed their eligibility through responses to a screening questionnaire, provided informed consent and were offered treatment, health and social service referrals if necessary. The study protocol consisted of an interviewer-administered questionnaire covering social, health and drug-use information; a depression assessment (Composite International Diagnostic Interview Short Form for Major Depression ${ }^{41}$ ); and an immunoassay antibody screening test of oral fluid for HIV, hepatitis C and hepatitis B. Assessments were performed on an anonymous basis (with each participant identified by a study code rather than by name), and all data were treated confidentially. Each subject received \$20 compensation for undergoing the assessment and all have been invited for follow-up assessments. For the analysis presented here, 28 cases were missing or excluded because of ambiguous responses; therefore, data for only 651 subjects were available for analysis.

The dependent variable in this study was self-reported overdose experience in the 6 months before assessment (referred to as an "overdose episode"). We defined an overdose experience as "a drug-use related experience where you lost consciousness and/or had convulsions because of too strong of a drug(s) or taking too much drug(s)." Bivariate analyses were performed, with the Pearson $\chi^{2}$ statistic, to assess the association between overdose episodes and self-reported sociodemographic factors (age, sex, ethnicity, city and homelessness status) and 21 other factors covering personal and living situation, income, drug consumption (alcohol, heroin, cocaine, crack, hydromorphone, benzodiazepines or other opioids), injection drug use and frequency, physical and mental health, detention and use of health services. Route of drug administration was assessed for drugs for which more than 1 route of administration was common (hydromorphone, heroin and cocaine). The association between overdose episodes and age was assessed with a 2-sample $t$ test. Marginally significant variables $(p<0.10)$ were examined with binary logistic regression to determine any independent effects and their respective odds ratios (ORs), with adjustment for sociodemographic factors.

\section{Results}

Key sociodemographic, drug-use and treatment characteristics of the OPICAN sample are presented in Table 1.

Overall, $112(17.2 \%)$ of the 651 subjects reported an overdose episode in the previous 6 months; among these, $42 / 111(37.8 \%)$ reported multiple episodes. In 63 cases $(56.3 \%)$ the person was attended by ambulance personnel, and $50(44.6 \%)$ received hospital attention during at least one of their recent overdose episodes. Almost one-quarter of the subjects ( 27 or $24.1 \%$ ) did not receive any formal or informal assistance (Table 2).

Overdose episodes were not significantly associated with any of the sociodemographic variables $(p>0.10)$, except age (OR 0.97, 95\% confidence interval [CI] 
0.95-1.00) and homelessness (OR 1.86, $95 \%$ CI $1.12-3.10)$. Other predictors of overdose were consumption of alcohol (OR 1.69, 95\% CI 1.07-2.67), consumption of benzodiazepines (OR 1.70, 95\% CI 1.13-2.57), concurrent use of opioids and nonopioids (OR 1.68, 95\% CI 1.03-2.73) and noninjection administration of hydromorphone in the past 30 days (OR 2.73, 95\% CI 1.37-5.46). There were also associations with depression (OR 1.73, 95\% CI 1.15-2.63), self-reported mental health problems (OR 1.51, 95\% CI 0.99-2.30) and involvement in drug treatment in the past 12 months (OR 1.78, 95\% CI 1.16-2.74).

When the factors identified as significant in the bivariate analyses were entered into a logistic regression analysis, homelessness, noninjection use of hydromorphone in the past 30 days and enrolment in drug treatment in the past 12 months emerged as significant predictors of overdose episodes $(p<0.05)$ (Table 3). Age was marginally significant (OR 0.98, 95\% CI 0.95-1.00, $p=0.082$ ).

The relations between overdose episodes and the 3 predictors of overdose identified by logistic regression analysis were examined with combined-sample data, an approach validated by the results of the Breslow-Day test of homogeneity of city-specific ORs $(p=0.06$ for drug treatment, 0.68 for homelessness and 0.38 for noninjection use of hydromorphone). However, separate city-specific $\chi^{2}$ analyses suggested that the overall significance of the associations of homelessness and noninjection use of hydromorphone with overdose episodes was largely driven by data from 2 cities: for homelessness, Vancouver (OR 2.42, 95\% CI 1.02-5.75) and, to a lesser extent, Montréal (OR $3.26,95 \%$ CI $1.26-8.43$ ) (for the latter $\chi^{2}$ analysis, $25 \%$ of cells had an expected count of less than 5); and for noninjection use of hydromorphone, Montréal only (OR 9.00, 95\% CI 1.56-51.87). The significance of drug treatment was mostly attributable to data from Toronto (OR 3.26, 95\% CI 1.28-8.33) and Québec (OR 5.10, 95\% CI $1.52-17.12$ ) (for the latter $\chi^{2}$ analysis, $25 \%$ of cells had an expected count of less than 5 ).

\begin{tabular}{|c|c|c|}
\hline \multirow{2}{*}{$\frac{\text { Characteristic }}{\text { Mean age (and SD), yr }}$} & \multicolumn{2}{|c|}{$\begin{array}{c}\text { No. (and \%) of } \\
\text { subjects* } \\
n=651\end{array}$} \\
\hline & 34.8 & $(9.4)$ \\
\hline No. of males & 434 & $(66.7)$ \\
\hline Ethnic background white & 444 & $(68.2)$ \\
\hline Living on the street & 97 & $(14.9)$ \\
\hline Use of nonopioid drugs† in past $30 \mathrm{~d}$ & 616 & $(94.6)$ \\
\hline Injection drug use in past $30 \mathrm{~d}$ & 524 & $(80.5)$ \\
\hline Drug treatment in past $12 \mathrm{mo}$ & 173 & $(26.6)$ \\
\hline
\end{tabular}

\section{Interpretation}

In this study we examined the prevalence of and the factors associated with nonfatal overdose episodes among illicit opioid users from 5 Canadian cities who were not receiving treatment. Almost 1 in 5 subjects reported an overdose episode during the 6 months before assessment, and of those reporting such an episode, more than 1 in 3 had experienced multiple episodes. Overdose episodes were common within our sample, as has been documented for populations of illicit opioid users elsewhere. ${ }^{2-8}$

Of every 5 subjects who reported an overdose episode, 2 had not received any kind of medical or emergency assistance. No association was found with sex, but age was inversely associated with occurrence of overdose. The latter finding, which is inconsistent with popular assumptions but which has been observed in other studies, suggests that such incidents are not more likely to occur among younger, less experienced drug users. ${ }^{5,11,42}$ However, we could not evaluate this finding further, because we had no information on duration of drug use.

After adjustment for sociodemographic and other variables, logistic regression analysis revealed 3 independent factors associated with overdose: homelessness, noninjection use of hydromorphone in the past 30 days and exposure to drug treatment in the past 12 months. The first of these associations is consistent with the literature, ${ }^{18,25,26}$ although in our study this result was driven primarily by the Vancouver subsample. Homelessness is a powerful social determinant of negative health status, and its association with poor health outcomes for drug users has been demonstrated previously. ${ }^{43,44}$

The association with noninjection use of hydromorphone was mainly attributable to data from the Montréal sample. The literature suggests that the risk of overdose is higher with injection of opioids than with other administration routes. ${ }^{28}$ However, further analyses revealed that this factor was significantly associated with benzodiazepine use $(r=0.201, p=$ 0.003 ), which itself demonstrated a bivariate association with

\begin{tabular}{|c|c|c|}
\hline Characteristic & No. (and & of subjects \\
\hline \multicolumn{3}{|l|}{ Overdose episodes in past 6 mo } \\
\hline At least 1 & $112 / 651$ & $(17.2)$ \\
\hline More than $1^{*}$ & $42 / 111$ & $(37.8)$ \\
\hline \multicolumn{3}{|l|}{ Assistance received $(n=112)$} \\
\hline Assisted by ambulance personnel & 63 & $(56.2)$ \\
\hline Treated in hospital & 50 & $(44.6)$ \\
\hline Received naloxone & 26 & $(23.2)$ \\
\hline Assisted by friends only $\dagger$ & 19 & $(17.0)$ \\
\hline No assistance & 27 & $(24.1)$ \\
\hline
\end{tabular}

*Percentage calculated with reference to the number of subjects who had at least 1 overdose. Data missing for 1 subject, so the denominator was 111 .

†No medical assistance. 
overdose. Therefore, noninjection use of hydromorphone may have served as a proxy for the concurrent use of benzodiazepines by subjects in our sample. The use of benzodiazepines (and other drugs) in conjunction with opioids is well documented as posing a greater risk for overdose. $21,22,29,30,45,46$

Finally, subjects who had been exposed to drug treatment in the year before assessment were more likely to report an overdose episode. The most common treatment types were detoxification $(62 / 172$ or $36.0 \%)$ and clinic-based methadone maintenance (38/173 or $22.0 \%)$. Previous research has shown the potential antitherapeutic or iatrogenic effects of treatment for overdose; ${ }^{31}$ for example, treatment may lower users' drug tolerance ${ }^{5}$ or facilitate unfavourable pharmacodynamics between prescription and nonprescription drugs (e.g., concurrent use of methadone and benzodiazepines).

Our study had several limitations. The fact that we were unable to determine the representativeness of the sample clearly limits the generalizability of our results to other populations of drug users in and beyond the study sites. Furthermore, by using self-reported data we may have missed overdose experiences that had been forgotten, improperly recognized (positive or negative bias) or wilfully not reported. However, research on memory and selfreported data of even a sensitive nature (e.g., criminal activity or sex risks) among illicit drug users has shown that validity is high. ${ }^{47,48}$

This study underlines the important role of housing and social determinants in general - in determining the health of marginalized populations. Housing and other forms of social support may help to reduce health risks for illicit drug users, including the risk of overdose. The demonstrated association of overdose episodes with use of multiple drugs requires further investigation. Clearly, measures are needed to increase awareness among users and care providers about the risks associated with consumption of both prescription and illicit substances. Further efforts are needed to untangle the complex dynamics of the potential antitherapeutic effects of treatment, as suggested by our data. Such efforts must take into account the fact that many treatment episodes for illicit drug users are suddenly or prematurely terminated, which leaves no opportunity for transition measures.

Further study is also needed to determine why so few subjects used emergency services for overdose episodes. Systematic provision to drug users of overdose resources and response training - including naloxone and training in cardiopulmonary resuscitation ${ }^{9,39}$ - may be one way to address these response gaps.

Our results suggest that a complex combination of factors is associated with overdose episodes among the illicit opioid users in the OPICAN study. Interventions are more likely to be effective if they can be directed to some of these specific causal factors.

\section{This article has been peer reviewed.}

From the Centre for Addiction and Mental Health, University of Toronto, Toronto, Ont. (Fischer, Rehm, Mun, Haydon, Baliunas); the Centre Hospitalier de l'Université de Montréal, Montréal, Que. (Brissette, Bruneau); the Université de Montréal, Montréal, Que. (Brochu); Foothills Hospital, Calgary, Alta. (el-Guebaly); the Institut nationale de santé publique du Québec, Québec, Que. (Noël); the BC Centre for Excellence in HIV/AIDS, Vancouver, BC (Tyndall); and the University of Alberta, Edmonton, Alta. (Wild)

Table 3: Variables associated with drug overdose within the past 6 months*

\begin{tabular}{|c|c|c|c|c|}
\hline \multirow[b]{2}{*}{ Variable† } & \multirow{2}{*}{$\begin{array}{c}\text { No. of } \\
\text { subjects }\end{array}$} & \multirow{2}{*}{$\begin{array}{c}\text { No. (and \%) } \\
\text { with overdose }\end{array}$} & \multicolumn{2}{|c|}{ OR (and 95\% Cl) } \\
\hline & & & Crude & Adjusted $\neq$ \\
\hline \multicolumn{5}{|l|}{$\begin{array}{l}\text { Social, health and } \\
\text { treatment characteristics }\end{array}$} \\
\hline Living on the street & 97 & $25(25.8)$ & $1.86(1.12-3.10)$ & $1.96(1.10-3.48)$ \\
\hline Depression§ & 322 & $68(21.1)$ & $1.73(1.15-2.63)$ & $1.26(0.78-2.01)$ \\
\hline Mental health problem & 211 & $45(21.3)$ & $1.51(0.99-2.30)$ & $1.17(0.71-1.91)$ \\
\hline $\begin{array}{l}\text { Drug treatment in past } \\
12 \mathrm{mo}\end{array}$ & 173 & $41(23.7)$ & $1.78(1.16-2.74)$ & $1.70(1.05-2.75)$ \\
\hline \multicolumn{5}{|l|}{ Drugs consumed $\uparrow$} \\
\hline Alcohol & 422 & $83(19.7)$ & $1.69(1.07-2.67)$ & $1.44(0.88-2.37)$ \\
\hline Benzodiazepines & 234 & $52(22.2)$ & $1.70(1.13-2.57)$ & $1.36(0.83-2.23)$ \\
\hline $\begin{array}{l}\text { Opioids in combination } \\
\text { with nonopioids }\end{array}$ & 458 & $88(19.2)$ & $1.68(1.03-2.73)$ & $1.63(0.97-2.73)$ \\
\hline \multicolumn{5}{|l|}{$\begin{array}{l}\text { Hydromorphone route of } \\
\text { administration }\end{array}$} \\
\hline No consumption (reference) & 434 & $69(15.9)$ & 1.00 & 1.00 \\
\hline Injection & 155 & $23(14.8)$ & $0.92(0.55-1.54)$ & $0.87(0.46-1.64)$ \\
\hline Oral, nasal, smoked & 62 & $20(32.2)$ & $2.52(1.40-4.55)$ & $2.37(1.20-4.71)$ \\
\hline
\end{tabular}

Note: $\mathrm{OR}=$ odds ratio, $\mathrm{Cl}=$ confidence interval.

*Variables were identified by bivariate analysis and were then subjected to logistic regression.

†Self-reported, except for depression.

fThe fully adjusted model included all variables shown in this table, as well as age, sex, ethnicity and city.

§Based on Composite International Diagnostic Interview Short Form for Major Depression. ${ }^{41}$

IIn past 30 days. 
Competing interests: None declared.

Contributors: Dr. Fischer, Dr. Brissette, Dr. Brochu, Dr. Bruneau, Dr. el-Guebaly, Ms. Noël, Dr. Rehm, Dr. Tyndall and Dr. Wild contributed substantially to the conception and design of the study and the interpretation of the data, either drafted or revised the paper critically for important intellectual content, and gave final approval for the version to be published. Dr. Mun, Ms. Haydon and Ms. Baliunas contributed substantially to the analysis and interpretation of the data, either drafted or revised the paper critically for important intellectual content, and gave final approval for the version to be published.

Acknowledgements: We acknowledge funding support for the Interdisciplinary Health Research Team on Illicit Opiate Addiction Research, Treatment and Policy from the Canadian Institutes of Health Research.

\section{References}

1. Cherubin CE, Sapira JD. The medical complications of drug addiction and the medical assessment of the intravenous drug user: 25 years later. Ann Intern Med 1993;119:1017-28.

2. Hser Y, Hoffman V, Grella C, Anglin M. A 33-year follow-up of narcotics addicts. Arch Gen Psychiatry 2001;58:503-8.

3. Rehm J. Modes de consommation et répartition des drogues en Suisse. In: Fahrenkrug H, Rehm J, Müller R, editors. Drogues illégales en Suisse 1990-93. La situation dans les cantons et en Suisse. Zürich: Seismo; 1995. p. 13-34.

4. Waal H. Overstating the case: methodological comments on "The effects of harm reduction in Amsterdam" by Buning and van Brussel. Eur Addict Res 1997;3:199-204.

5. Darke S, Hall W. Heroin overdose: research and evidence-based intervention. 7 Urban Health 2003;80:189-200.

6. Warner-Smith M, Darke S, Day C. Morbidity associated with non-fatal heroin overdose. Addiction 2002;97:963-7.

7. Darke S, Ross J. Overdose risk perceptions and behaviours among heroin users in Sydney, Australia. Eur Addict Res 1997;3:87-92.

8. Vingoe L, Welch S, Farrell M, Strang J. Heroin overdose among a treatment sample of injecting drug misusers: accident or suicidal behaviour. 7 Subst Use 1999;4:88-91.

9. Seal K, Downing M, Kral AH, Singleton-Banks S, Hammond JP, Lorvick J, et al. Attitudes about prescribing take-home naloxone to injection drug users for the management of heroin overdose: a survey of street-recruited injectors in the San Francisco Bay Area. F Urban Health 2003;80:291-301.

10. Davidson P, Ochoa K, Hahn J, Evans J, Moss A. Witnessing heroin-related overdoses: the experiences of young injectors in San Francisco. Addiction 2002;97:1511-6.

11. Powis B, Strang J, Griffiths P, Taylor C, Williamson S, Fountain J, et al. Selfreported overdose among injecting drug users in London: extent and nature of the problem. Addiction 1999;94:471-8.

12. Remis R, Leclerc P, Routledge R, Taylor C, Bruneau J, Beauchemin J, et al. Consortium to characterize injection drug users in Canada (Montreal, Toronto and Vancouver). Final report. Toronto: Self-published; 1998.

13. Fischer B, Rehm J. The case for a heroin substitution treatment trial in Canada. Can 7 Public Health 1997;88:367-70.

14. Fischer B, Rehm J, Blitz-Miller T. Injection drug use and preventive measures: a comparison of Canadian and Western European jurisdictions over time. CMA7 2000;162(12):1709-13.

15. Millar J. HIV, bepatitis, and injection drug use in British Columbia-Pay now or pay later? Victoria: Office of Provincial Health Officer; 1998.

16. Wood E, Tyndall MW, Spittal PM, Li K, Kerr T, Hogg RS, et al. Unsafe injection practices in a cohort of injection drug users in Vancouver: Could safer injecting rooms help? CMA7 2001;165(4):405-10.

17. Fischer B, Medved W, Gliksman L, Rehm J. Illicit opiates in Toronto: a profile of current users. Addict Res 1999;7:377-415.

18. Preti A, Miotto P, de Coppi M. Death by unintentional illicit drug overdose in Italy, 1984-2000. Drug Alcohol Depend 2002;66:275-82.

19. Torralba L, Brugal M, Villalbi J, Tortosa M, Toribio A, Valverde J. Mortality due to acute adverse drug reactions: opiates and cocaine in Barcelona, 198993. Addiction 1996;91:419-26.

20. Hickman M, Madden P, Henry P, Baker A, Wallace C, Wakefield J, et al. Trends in drug overdose deaths in England and Wales 1993-1998: methadone does not kill more people than heroin. Addiction 2003;98:419-25.

21. Sergeev B, Karpets A, Sarang A, Tikhonov M. Prevalence and circumstances of opiate overdose among injection drug users in the Russian Federation. 7 Urban Health 2003;80:212-9.
22. Darke S, Ross J, Hall W. Overdose among heroin users in Sydney, Australia I. Prevalence and correlates of non-fatal overdoes. Addiction 1996;91:405-11.

23. Gossop M, Griffiths P, Powis B, Williamson S, Strang J. Frequency of nonfatal heroin overdose: survey of heroin users recruited in non-clinical settings. BM7 1996;313:402.

24. Davidson P, McLean R, Kral A, Gleghorn A, Edlin B, Moss A. Fatal heroinrelated overdose in San Francisco, 1997-2000: a case for targeted intervention. 7 Urban Health 2003;80:261-73.

25. Marzuk P, Tardiff K, Leon A, Hirsch C, Stajic M, Portera L, et al. Poverty and fatal accidental drug overdoses of cocaine and opiates in New York City: an ecological study. Am 7 Drug Alcobol Abuse 1997;23:221-8.

26. Jones R, Gruer L, Gilchrist G, Seymour A, Black M, Oliver J. Recent contact with health and social services by drug misusers in Glasgow who died of a fatal overdose in 1999. Addiction 2002;97:1517-22.

27. Klee H, Morris J. Factors that characterize street injectors. Addiction 1995;92: 1349-52.

28. Brugal M, Barrio G, de la Fuente L, Regidor E, Royuela L, Suelves J. Factors associated with non-fatal heroin overdose: assessing the effect of frequency and route of heroin administration. Addiction 2002;97:319-27.

29. McGregor C, Darke S, Ali R, Christie P. Experience of non-fatal overdose among heroin users in Adelaide, Australia: circumstances and risk perceptions. Addiction 1998;93:701-11.

30. Seal KH, Kral AH, Gee L, Moore LD, Bluthenthal RN, Lorvick J, et al. Predictors and prevention of nonfatal overdose among street-recruited injection heroin users in the San Francisco Bay Area, 1998-1999. Am 7 Public Health 2001;91:1842-6.

31. Buster M, van Brussel G, van den Brink W. An increase in overdose mortality during the first 2 weeks after entering or re-entering methadone treatment in Amsterdam. Addiction 2002;97:993-1001.

32. Strang J, McCambridge J, Best D, Beswick T, Bearn J, Rees S, et al. Loss of tolerance and overdose mortality after inpatient opiate detoxification: follow up study. BMF 2003;326:959-60.

33. Wagner-Servais D, Erkens M. Methadone-related deaths associated with faulty induction procedures. 7 Maint Addict 2003;2:57-67.

34. Drummer OH, Syrjanen M, Opeskin K, Cordner S. Deaths of heroin addicts starting on a methadone maintenance programme [letter]. Lancet 1990;335:108.

35. Caplehorn J. Deaths in the first two weeks of maintenance treatment in NSW in 1994: identifying cases of iatrogenic methadone toxicity. Drug Alcohol Rev 1998;17:9-17.

36. Seaman S, Brettle R, Gore S. Mortality from overdose among injecting drug users recently released from prison: database linkage study. BM7 1998;316: 426-8.

37. Tobin K, Latkin C. The relationship between depressive symptoms and nonfatal overdose among a sample of drug users in Baltimore, Maryland. 7 Urban Health 2003;80:220-9.

38. Darke S, Ross J, Hall W. Overdose among heroin users in Sydney, Australia: II. Responses to overdose. Addiction 1996;91:413-7.

39. Dietze P, Cantwell K, Burgess S. Bystander resuscitation attempts at heroin overdose: Does it improve outcomes? Drug Alcohol Depend 2002;67:213-8.

40. Watters J, Biernacki P. Targeted sampling: options for the study of hidden populations. Soc Probl 1989;36:416-30.

41. Patten SB. Performance of the Composite International Diagnostic Interview Short Form for Major Depression in community and clinical samples. Chronic Dis Can 1997;18:109-12.

42. Darke S. Polydrug use and overdose: overthrowing old myths [editorial]. $A d$ diction 2003;98:711.

43. Martens W. A review of physical and mental health in homeless persons. Public Health Rev 2001;29:13-33.

44. Hwang S. Homelessness and health. CMA7 2001;164(2):229-33.

45. Darke S, Hall W. Levels and correlates of polydrug use among heroin users and regular amphetamine users. Drug Alcobol Depend 1995;39:231-5.

46. Coffin P, Galea S, Ahern J, Leon A, Vlahov D, Tardiff K. Opiates, cocaine and alcohol combinations in accidental drug overdose deaths in New York City, 1990-98. Addiction 2003;98:739-47.

47. Fiske S, Taylor S. Social cognition. New York: McGraw-Hill; 1991.

48. Darke S. Self-report among injecting drug users: a review. Drug Alcobol Depend 1998;51:253-63.

Correspondence to: Dr. Benedikt Fischer, Social, Prevention and Health Policy Research, Centre for Addiction and Mental Health, 33 Russell St., Room 2035, Toronto ON M5S 2S1; fax 416 2604156; Benedikt_Fischer@camh.net 